\title{
Media Consumption and Civic Engagement: The Reasoned Action Theory as a Way Forward to Determine The Relationship
}

\author{
JOSEPH RAMANAIR \\ Universiti Malaysia Sarawak
}

\begin{abstract}
Communication is important to enable ideas to be transformed into informed actions. As such, the media used for such communication is crucial and play an important role in broadcasting the information. The proliferation of the Internet has greatly enhanced the important role of the media and changed the landscape of the media industry. In addition to conventional media, consumers are now able to access a variety of social media applications. Both types of media are important and needs to be considered as it continues to be consumed across demographics and play important roles in communicating information. Further, both types of media are capable of informing and shaping the views of consumers in a variety of areas from the political to the social. The important question remains as to whether increased availability, access, and connectivity to the various types of media and the information provided have enabled opportunities to media consumers to engage in discussions to stimulate civic engagement leading to activism. Research investigating users' media consumption and civic engagement with issues explored is largely not well theorised and often offer inconclusive or conflicting results. As such, the ensuing discussion proposes a way forward utilising the Reasoned Action Theory to determine the relationship between media consumption and civic engagement.
\end{abstract}

Keywords: Communication, media consumption, civic engagement, reasoned action theory, behaviour.

\section{INTRODUCTION}

Communication plays an important role in society. It is capable of creating ideas and actions that can mobilise thinking and movements. One impactful form of communication is writing. The establishment of the printing press resulted in written ideas being shared and distributed widely. These developments have contributed to the existence of the print newspapers and much later radio, telephone, and television.

The advent of the Internet technology has advanced communication to bridge time and space. Social media has increasingly become an indispensable platform for communication given its rapidity in delivering information within record time. Online news portals and applications have not only enabled vital news and information to be disseminated within minutes but have also connected to a wider audience and created consumers who can feedback views and news, and even create their own media communication platforms.

The proliferation of the communication media advanced by the rapid growth of Internet technology has thus not only changed the landscape of the media industry but has also increased connectivity. Media communication remains a relevant tool to broadcast information and also provide entertainment capable of persuading and influencing consumers. The important question remains as to whether increased connectivity has provided opportunities for media users to engage in discussions to stimulate greater engagement in civic life (Skoric, Zhu, Goh, \& Pang, 2016; Wilnatt \& Aw, 2014). 